\title{
Leakage Currents of Zinc Oxide Surge Arresters in 22 kV Distribution System Using Thermal Image Camera
}

\author{
Wichet Thipprasert, Prakasit Sritakaew \\ Department of Electrical Engineering, Faculty of Engineering, Rajamangala University of Technology Lanna \\ Chiang Rai, Chiang Rai, Thailand \\ Email: wichet thhip@rmutl.ac.th, prakasit.sri@gmail.com
}

Received December 2013

\begin{abstract}
Zinc Oxide (ZnO) surge arresters (SAs) experience thermal runaway when the temperature exceeds the acceptable limit. This phenomenon is associated with the increase in resistive leakage current due to degradation. This paper presents the electrical performance of $\mathrm{ZnO}$ SAs in $22 \mathrm{kV}$ distribution systems using thermal image camera under the power frequency AC operating voltages. When $\mathrm{ZnO}$ surge arresters are installation takes a long time in distribution system over more than 5 years. For the experimental study, as ZnO installation takes a long time over 6 years the leakage current is $63.9 \mathrm{~mA}$, temperature differences were measured over a period of time over 14 degree Celsius. This data will be useful as a guideline for solving problems and reducing power loss from leakage current. Moreover, it will be useful in predicting lifetime of ZnO SAs.
\end{abstract}

\section{Keywords}

Electrical Performance; Surge Arrester; Thermal Image Camera

\section{Introduction}

High voltage systems are often subject to transient overvoltages of internal or external origin. The resultant surges travel along the transmission line and can cause damage to unprotected terminal equipment. Corona losses and the earth return path can attenuate and distort the surges, but the magnitude of the surge may still exceed the insulation level of the equipment. SAs provide a limitation of the overvoltage to a chosen protective level. The superiority of the recently developed $\mathrm{ZnO}$ material over the earlier used silicon carbide (SiC) renewed interest and boosted the use of SA protection.

The excellent voltage-current nonlinearity of $\mathrm{ZnO}$ elements have been successfully utilized to eliminate series gap in ZnO SA, which are replacing conventional series gap arresters with SiC nonlinear resistors. However, in its initial stage of development, ZnO SA had to be so designed that the normal operating voltage stress applied to the elements was relatively low to minimize degradation due to the normal operating voltage stress, resulting in a restricted improvement of protective characteristics. In other words, the resistance values are decreased as temperature rises. It is also well known that when temperature on the $\mathrm{ZnO}$ elements exceeds the limit by ab- 
sorbing surge energy, the phenomenon of thermal runaway occurs as a result of increased heat generation caused by subsequent ac voltage application. SA must not only be thermally stable at normal operating stress, but must also discharge various transient overvoltage energies and return to the former thermally stable condition from the temporary high temperature state. The latter is termed transient thermal stability. In the following text, transient thermal stability is abbreviated to thermal stability. When the operating stress becomes higher, the absorbed energy for transient overvoltages becomes larger because the current created by transient overvoltages is larger. Therefore, the discharge capability requirement and the transient thermal stability are more severe in the case of high operating stress [1-3].

$\mathrm{ZnO}$ SAs are fundamental elements of protecting systems of electric devices against overvoltages. They contain varistores, which have $\mathrm{ZnO}$ as the main constituent as well as small amounts of other metal oxides. SAs are exposed to transient effect of overvoltages generated as a result of lightning discharges, switching and damage states in electric power systems.

This thermal runaway phenomenon can be studied as a problem of balance between heat generation and heat dissipation. Conventionally, this problem has been discussed simply as static phenomenon on the basis that heat generation of $\mathrm{ZnO}$ elements was uniform along the $\mathrm{ZnO}$ columns, while their heat dissipation was equally uniform [1,3]. Actual measurements were also conducted on single or several series-connected $\mathrm{ZnO}$ elements that possessed different heat dissipating conditions.

The electrical energy is then converted and stored in the metal oxide valve elements as thermal energy, thus resulting in a temperature rise above normal operating levels. An increase of valve element temperature can upset the thermal balance in the arrester assembly, resulting in a thermal runaway. Since, the thermal capabilities of gapless metal oxide SAa depend on ambient temperature and solar radiation gain, both factors must be considered in application studies. Such studies can now be carried out using a relatively simple and yet representative model of the thermal properties at the arrester valve element and housing [1].

In this research, in order to understand the thermal and electrical properties of a ZnO SAs $50 \mathrm{~Hz}$ AC voltage changes in leakage current were measured. The temperature distribution appearing on the ZnO SA was observed using a forward looking infrared camera. In particular, the correlation between the thermal and electrical properties of a ZnO SA was analyzed experimentally. From this analysis, the thermal phenomena resulting from the heat generation and dissipation of the $\mathrm{ZnO}$ SA were interpreted.

\section{Thermal Performance of Zno Surge Arrester [1]}

The thermal stability of ZnO SA is affected by ambient temperature and heat dissipation capability, impulse degradation and ageing. To obtain thermal stability, the electrical power dissipation in the element must be balanced against heat output to the environment. Near the thermal equilibrium, it is possible to express the thermal dissipation capacity Q of a SA as:

$$
Q=C_{T}\left(T-T_{a}\right)
$$

where $T$ is the temperature of $\mathrm{ZnO}$ valve elements, Ta is the ambient temperature and $C_{T}$ the thermal dissipation factor. The heat generation, $P$, which is voltage and material composition dependent, may be approximated by

$$
T=A e^{\left(W_{c} / k T\right)}
$$

where $W_{c}$ is the activation energy, $k=0.86 \times 10 \mathrm{eV} / \mathrm{K}$ (Boltzmann constant), $T$ is the temperature of the material and $A$ depends on the applied voltage level and the physical dimensions of the valve elements. The above curves are shown schematically in Figures 1 and 2. For an ambient temperature Ta and an applied voltage V, the two curves intersect at two points $X$ and $Y$. The lower point $X$ is at a stable operating temperature $T x$ and is referred to as the lower limit stability point. The upper point $Y$ is also at a stable operating temperature $T y$ and is called the upper limit stability point. At these temperatures, the power input equals the power output.

\section{Thermal Runaway Phenomenon of Zn0 Surge Arrester [1,3]}

When a $\mathrm{ZnO} \mathrm{SA}$ is connected to a distribution system, resistive leakage current is less than $1 \mathrm{~mA}$ flows through the arrester, as shown in Figure 3. However, when large surge energy of power system is absorbed, the temperature of $\mathrm{ZnO}$ elements increases, causing the resistance value to decrease. As a result, the leakage current becomes greater and the heat generation increases. Even if the heat generation increases, the temperature rise by surge energy absorption T1 shown in Figure 4 may be below the certain temperature limit intrinsic to the SA. 


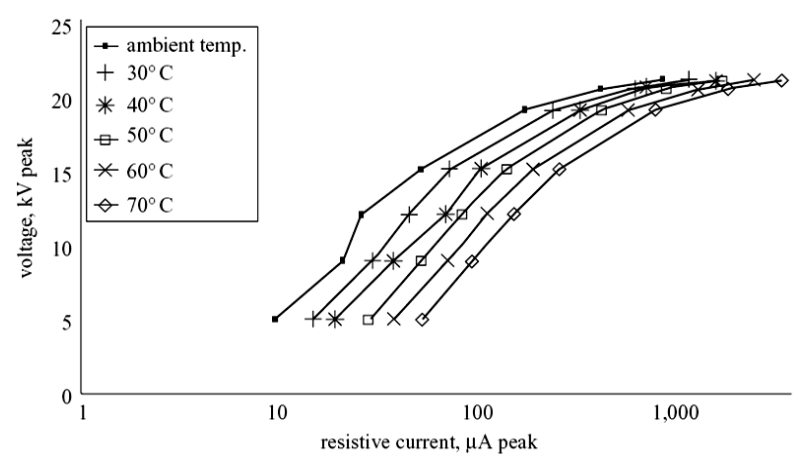

Figure 1. Temperature dependence of $\mathrm{ZnO}$ voltage current characteristic.

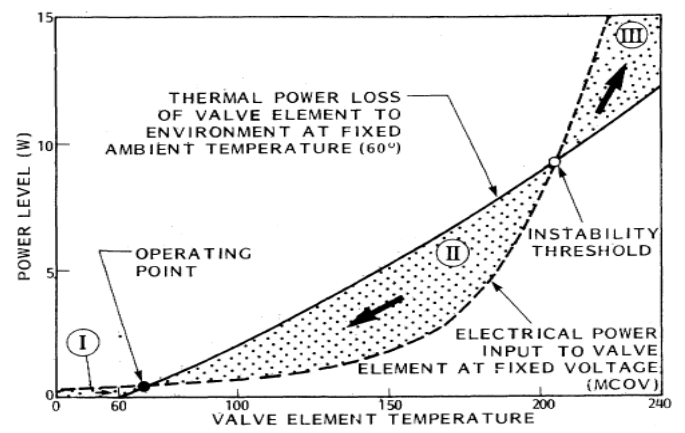

Figure 2. Evaluation of $\mathrm{ZnO}$ surge arrester steady state stability using the heat loss-input characteristic.

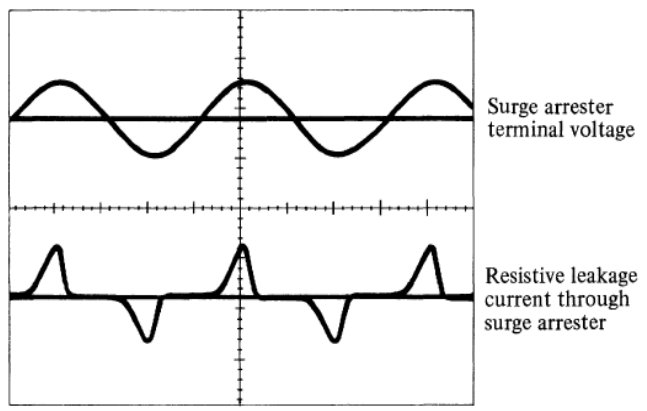

Figure 3. Resistive leakage current flowing through surge arrester when AC voltage is supplied.

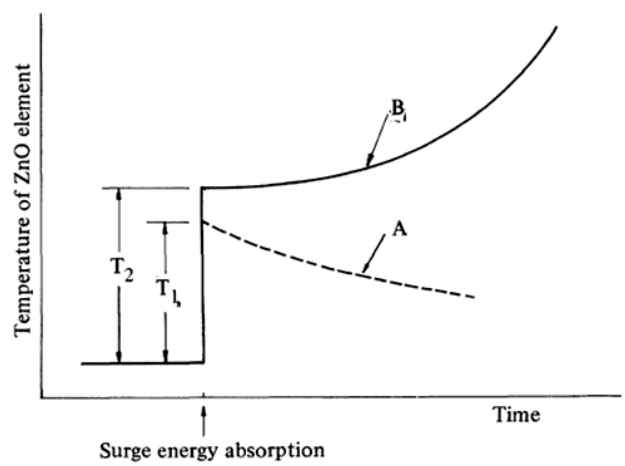

Figure 4. Thermal runaway phenomenons on zincoxide surge arrester. 


\section{Test Specimens, Setups, and Procedures}

\subsection{Test Specimens}

The specimens are $\mathrm{ZnO}$ surge arresters in $22 \mathrm{kV}$ distribution systems as shown in Figure 5 consist ZnO SA No A $21 \mathrm{kV}$ rated voltage installation takes a long time in distribution system over more than 6 - 7 years, No B 21 $\mathrm{kV}$ rated voltage installation takes a long time in distribution system over more than 5 year and No B $21 \mathrm{kV}$ rated voltage installation takes a long time in distribution system over more than 5 - 6 years and Table 1 shows the parameters of the samples test.

\subsection{Test Setup}

The test circuit of ZnO SA is provided schematically in Figure 6. The voltage elevation transformer is supplied by a Variac, thus resulting in a controlled gradual voltage increase. The transformer secondary coil is connected in series resistance $\mathrm{R} 0=2 \mathrm{M} \Omega$ and parallel with a capacitive voltage divider comprised of capacitors $\mathrm{C} 1$ and $\mathrm{C} 2$ respectively. In parallel with the voltage divider is the series connected of the insulator. The voltage across C2 is measured by a scope meter (190B Scope Meter Series: Fluke) and connected to a computer where it is recorded and visually displayed with the use of appropriate software. The technical characteristics of the capacitors C1 and C2 were 224 pF, $100 \mathrm{kV} / 50 \mathrm{~Hz}$ and $2 \mu \mathrm{F}, 1000 \mathrm{~V} / 50 \mathrm{~Hz}$, respectively.

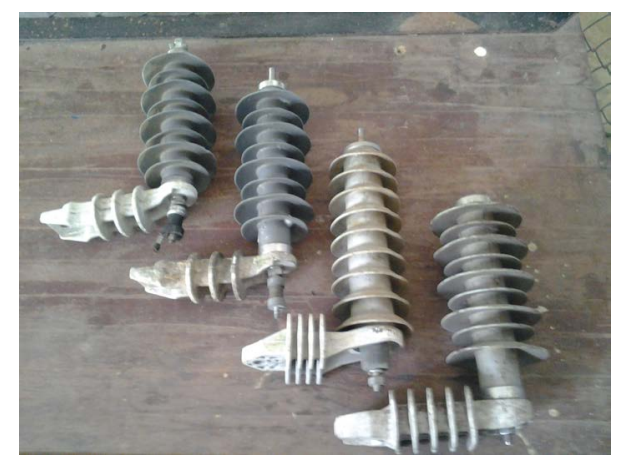

Figure 5. Test objects.

Table 1. Parameters of $\mathrm{ZnO}$ surge arrester.

\begin{tabular}{cccc}
\hline No. & Material & Rated Voltage $(\mathrm{kV})$ & installation takes a long time \\
\hline A & Polymer coat & 21 & $6-7$ years \\
B & Polymer coat & 21 & 5 years \\
C & Polymer coat & 21 & $5-6$ years \\
\hline
\end{tabular}

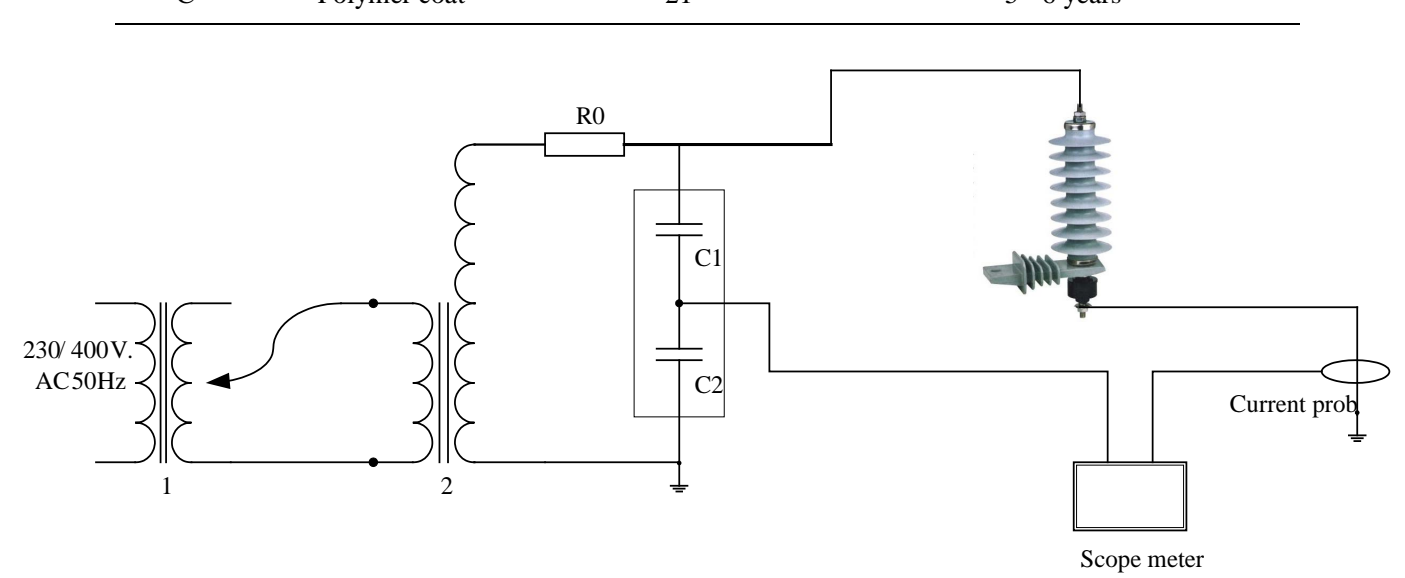

Figure 6. Schematic of testing. 


\subsection{Test Procedures}

The research was carried out on three ZnO SAs of $22 \mathrm{kV}$ distribution system of PEA. It is installation in distribution system over more than 5 years with parameter given in the Table $\mathbf{1}$. The experimental set-up is schematically shown in Figure 6. Referring to the test standard [1-3], the test procedures in the paper were as follows. After the connected circuit in Figure 6 completely, ac voltage was applied to the specimens and increased at a constant rate till the voltage is $18 \mathrm{kV}$. Then ac voltage supplied to specimens is a long time 3 hours. The thermal image camera (Fluke Ti32) records the temperature profile and the leakage current, as shown in Figure 8 and Table 2.

\section{Test Results of ZnO Surge Arrester}

The results form experiments are shown in Table 2, Figures 7 and 8. From Figure 8 shows the temperature of the central $\mathrm{ZnO}$ element as a function of time during the IEC type test [4,5]. The result experiments arrester No A maximum temperature of arrester increasing to 42.5 degree Celsius as ambient temperature is 27.1 degree Celsius, leakage current increase to $63.9 \mathrm{~mA}$. Arrester No B maximum temperature of arrester increasing to 49.1 degree Celsius as ambient temperature is 25.6 degree Celsius, leakage current increase to $46.2 \mathrm{~mA}$.

And arrester No C maximum temperature of arrester increasing to 46.3 degree Celsius as ambient temperature is 25.2 degree Celsius, leakage current increase to $37.6 \mathrm{~mA}$. However, the temperature of ZnO surge arrester No $\mathrm{C}$ is over than all $\mathrm{ZnO}$ surge arrester but leakage current of less than No A and No B because installation takes a long time in distribution system is over than all $\mathrm{ZnO}$ surge arrester. Therefore the temperature of ZnO surge arrester can be used for estimation of leakage current.

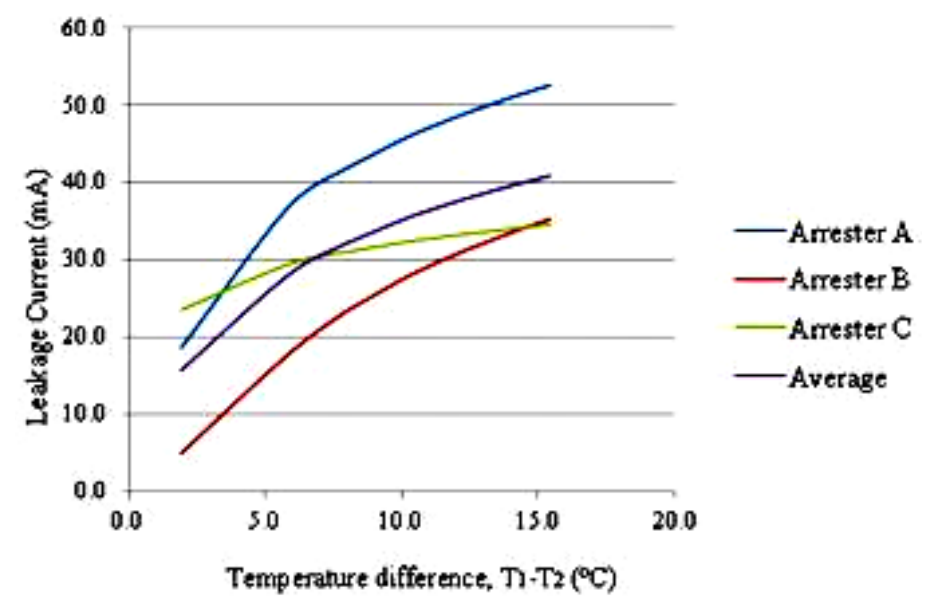

Figure 7. Temperature and leakage current curve.

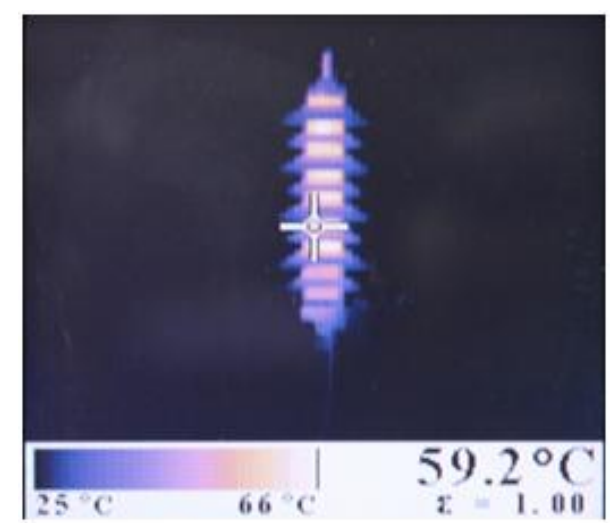

Figure 8. Temperature of arrester with $18 \mathrm{kV}$ ac voltages applied 
Table 2. The leakage current and temperature of arresters; $18 \mathrm{kV}$ ac voltage applied.

\begin{tabular}{ccccc}
\hline $\begin{array}{c}\text { Arrester } \\
\text { No. }\end{array}$ & $\begin{array}{c}\text { Leakage } \\
\text { current }(\mathrm{mA})\end{array}$ & $\begin{array}{c}\text { Maximum Temperature } \\
\text { of arrester }\left(\mathrm{T}_{1},{ }^{\circ} \mathrm{C}\right)\end{array}$ & $\begin{array}{c}\text { Ambient Temperature } \\
\left(\mathrm{T}_{2},{ }^{\circ} \mathrm{C}\right)\end{array}$ & $\begin{array}{c}\text { Temperature Difference } \\
\left(\mathrm{T}_{1}-\mathrm{T}_{2},{ }^{\circ} \mathrm{C}\right)\end{array}$ \\
\hline \multirow{2}{*}{$\mathrm{A}$} & 31.2 & 36.2 & 30.4 & 5.8 \\
& 42.8 & 41.3 & 28.9 & 12.4 \\
& 63.9 & 42.5 & 27.1 & 15.4 \\
$\mathrm{~B}$ & 33.9 & 40.2 & 26.2 & 14 \\
& 36.8 & 44.5 & 25.9 & 18.6 \\
& 46.2 & 49.1 & 25.6 & 23.5 \\
$\mathrm{C}$ & 30.5 & 32.8 & 25.2 & 7.6 \\
& 34.1 & 42 & 25.1 & 16.9 \\
& 37.6 & 46.3 & 25.2 & 21.1 \\
\hline
\end{tabular}

\section{Conclusions}

The thermal and electrical performances of ZnO SA were experimentally investigated. The results can be summarized as follows.

The total leakage current flowing through the Zno SA under power frequency is the sum of capacitive and resistive currents. The temperature profiles of Zno SAs are observed by thermal imager and the leakage current. Initially, the nominal voltage and leakage current is $63.9 \mathrm{~mA}$. The temperature of Zno SAs is close to the ambient temperature. Increase in the leakage current results in increase of the temperature profile.

Results from the experiment are used for $\mathrm{ZnO}$ surge arresters are installation takes a long time in distribution system over more than 5 years. These results can be guideline for solving problems and reducing power loss due to leakage current. Moreover, it will be useful to predict lifetime of $\mathrm{ZnO}$ SAs installed in distribution system.

\section{References}

[1] Haddad, A. and Warne, D. (2004) ZnO Surge Arresters. Advance in High Voltage Engineering, lET Power \& Energy Series, 40, 191-215.

[2] Lee, S.B., Lee, S.L. and Lee, B.K. (2009) Analysis of Thermal and Electrical Properties of ZnO Arrester Block. Current Applied Physics, 10, 176-180.

[3] Nishiwaki, S., Kimura, H., Satoh, T., Mizoguchi, H. and Yanabu, S. (1984) Study of Thermal Runaway/Equivalent Prorated Model of a ZnO Surge Arrester. IEEE Transaction on Power Apparatus and Systems, PAS-103, 413-421. http://dx.doi.org/10.1109/TPAS.1984.318260

[4] (1986) IEC Publ.815, First Edition. Guide for the Selection of Insulators in Respect of Polluted Conditions. International Electrotechnical Committee.

[5] (2004) International Standard of Surge Arrester IEC60099-4 Edition 2.1:2004 Consolidated With Amendment 1: 2006 Section 6.9 Operating Duty, Section 10 Test Requirement on Polymer-Housed Arresters and Annex B Test to Verify Thermal Equivalency Between Complete Arrester and Arrester Section, IEC60099-4. 